IMAGENS DA ARQUEOLOGIA *

Videodisco Laser

OS BANCOS DE IMAGENS

Política da DBMIST

\section{SERGE CALCALY}

Encarregado da Missão na Direction des Bibliothèques, des Musées et de I'Information Scientifique et Technique Ministère de la Recherche et de l'Enseignement Supérieur

Paris

O videodisco interativo, isto é, comandado por um computador - grande ou pequeno - é certamente uma das soluções do futuro, a mais eficaz para a estocagem e a difusão de imagens.

A DBMIST lançou um programa de experimentação visando avaliar o videodisco nos planos tecnológico, documentário e ergonômico. Além disso, os poderes públicos acabaram por se sensibilizar em interesse de uma nova tecnologia promissora.

E com este objetivo que a DBMIST decidiu sustentar o projeto comum de duas fototecas de arqueologia, a do Institut de Recherches sur l'Architecture Antique e a do Centre de Recherche sur la Mosaïque e do Centre de Recherches sur les Traitements Automatisés en Archéologie Classique. O videodisco Images de l'Archéologie reúne as imagens que ilustram os três bancos de dados constituídos por estes organismos.

A arqueologia é um terreno privilegiado para a experimentação da consulta interativa de bancos de imagens em videodisco. O recurso à imagem é indispensável no trabalho da arqueologia. Viático da pesquisa arqueológica, a imagem permite o estudo de objetos distantes, destruídos ou inacessíveis. Interpretar os objetos, ordená-los, recuperar sua identidade apagada pelo tempo, necessidade de comparações, de aproximações, implica finalmente na restituição do objeto na sua globalidade como expressāo da cultura de um grupo humano em uma dada época.

A contribuição do videodisco na difusão da cultura científica deveria ser um dos interesses maiores desta tecnologia. Assim, no caso presente, a implantação do videodisco poderia ser considerada tanto nos centros de pesquisa arqueológica, nas fototecas, nas escolas francesas no estrangeiro, quanto próximo ao grande público, em museus, bibliotecas, bem como nas unidades de formação e de pesquisa (UFR) do ensino superior the faria desempenhar um papel de auxílio à formação, de assistência, na preparação de futuros arqueólogos.

A natureza das imagens registradas, a diversidade dos sítios de interrogação considerados, tudo concorre para que, para além do mundo de pesquisa onde nasceu, este videodisco vise os diversos e numerosos públicos da arqueologia.

\section{IMAGENS DA} ARQUEOLOGIA

Um primeiro videodisco para a arqueologia clássica

RENÉ GINOUVÈS

Professor na Université de Paris $X$ Responsável pela UA 375 CNAS - Université de Paris $X$

Este videodisco, acoplado a três bancos de dados documentários, provavelmente é o primeiro no domínio da

* Tradução de Alvaro H. Allegrette (Pós-Graduaçăo de Antropologia Social - FFLCH-USP) do original francês publicado conjuntamente em 1986 pelo Ministère de la Recherche et de l'Enseignement Supérieur, pelo CNRS/Université de Paris X e pelo CNRS/Université de Paris $I$. 